\title{
Analysis on the Talent Training Program and Educational Administration by Fujian and Taiwan Cooperation Projects
}

\author{
Baoxiu Li \\ The Youth League Committee \\ Minjiang University \\ Fuzhou, Fujian, China \\ lbxiu81@163.com
}

\begin{abstract}
Fujian and Taiwan joint training project gives full play to the advantages of professional teachers and majors of universities in Fujian and Taiwan, which is of great significance in promoting the reform and development of higher education in Fujian province. However, the cross-straits different political, economic and educational management mechanism, result in obvious differences in the concept of running school, talent training mode and student education management. This paper selects five representative crossStrait Universities as examples, to give a detailed analysis of the advantages and disadvantages on the cooperative talent training program between Fujian and Taiwan, and to put forward the reform direction of the talent training mode based on the high- quality professionals, curriculum system, teaching practice and practice alliance.This paper also analyzes the existing problem which is related to the student management in the mode of the cooperative education of cross-strait universities, and explores the implementation path of constructing a new mode of education management, to promote cross-strait integration of the ideological and political education.
\end{abstract}

Keywords-Fujian colleges; Fujian and Taiwan; Talent training program; Students educational administration;

\section{INTRODUCTION}

In recent years, the cross-strait relationship has entered an era of communication, cooperation, integration and development. In May 2009, the State Council promulgated the "opinions" about speeding up the construction of the West Strait Economic Zone in Fujian Province. With Fujian Province being given the pilot policy of the exchanges and cooperation with Taiwan, Fujian also put forward the strategic plan to deepen cross-strait cooperation in education In 2010 the talent project joint training of Fujian and Taiwan (the cooperation between Fujian and Taiwan project) opened, which was the start in the cross-strait cooperation in education. Building professional "sub docking" education mode gave full play to the professional teachers in Colleges and universities in Fujian and Taiwan, which was of great significance in promoting the reform and development of Fujian higher education. Fujian Province giving full play to the advantages of Wuyuan culture of Fujian and Taiwan launched the "school enterprise", the joint training program of Fujian and Taiwan colleges. The number of college students to learn in Taiwan colleges has been increasing. In 2013, our province sent 226 batches, that is 3,315 students in various forms to Taiwan university (not including the diploma students to study in Taiwan). Along with the deepening of cooperation between Fujian and Taiwan education, obvious differences emerged in terms of educational philosophy, talent training mode and educational administration of the students because of the different political, economic and educational management mechanism, which also brings a challenge in cooperation between Fujian and Taiwan. According to a survey, the current cross-strait exchanges cooperation had some problems in student management, and students were not satisfied with the cross- strait higher educational joint training mode, infrastructure, educational resources, learning environment, learning exchanges and other aspects .the rate of satisfaction did not exceed $50 \%{ }^{[1]}$ Therefore, in the new era, how to optimize the program of training talents and how to innovate the students educational administration mode between Fujian and Taiwan is an important research subject.

\section{THE ANALYSIS OF THE BASIC SITUATION OF FUJIAN} AND TAIWAN COLLEGES AND UNIVERSITIES COOPERATIVE

EDUCATION AND THE CROSS-STRAIT COLLEGES AND UNIVERSITIES TALENT TRAINING PROGRAM

According to incomplete statistics, as of May, 2009, 298 colleges and universities in Mainland, and 108 universities and colleges in Taiwan signed an agreement of cooperation and exchange ${ }^{[2]}$. In 2013, our province sent 226 batches, that is 3,315 students in various forms to Taiwan university (not including the diploma students to study in Taiwan). In 2010, Fujian Normal University, Minjiang University, Fujian University of Technology, Xiamen University of Technology, Sanming university and Shih Hsin University in Taiwan, Chinese Culture University and other universities used learning mode of segmented docking "3+1" and "double campuses". In the period of the four years of undergraduate study, students spent three years 
learning in Mainland universities and one year learning in Taiwan cooperative universities. Up to 2011, a total of 27 colleges and universities and 142 professions, including Minjiang University had been approved, and the enrollment had reached 6000 people $^{[3]}$.

The talents training programs of the major cooperative colleges and universities are all proved by many aspects, and are determined in accordance with the analysis of the actual demand of the talent market, whose advantages are obvious. However, due to some objective factors, there are still some problems to be improved. The following several representative cross-straits University are selected as examples to analyze the advantages and disadvantages of the cooperative talent training program between Fujian and Taiwan.

\section{A. Chinese Culture University and Straits Institute of Minjiang University}

Taiwan Chinese Culture University and Minjiang University are cooperated on the mode of the " $3+1$ " Dual Campuses. The introduction of high-quality Taiwan curriculum system, management experience and the internationalization of teachers, more than $1 / 3$ professional courses undertaken by the Taiwan school teachers s, fully guarantee the high-quality program In order to give full play to the advantages of cooperation between Fujian and Taiwan, to enable students to maximize the absorption of Taiwan high- quality resources, Chinese Culture University will send teachers with a doctoral degree, with the experience of studying in Europe and the United States, and with rich teaching experience to Straits Institute of Minjiang University, teaching a course for the freshman, sophomore students. And most of the professional courses will be arranged to learn in the third semester in Taiwan, while in the fourth semester the teachers from Taiwan will come to Fujian to guide the students to write the thesis and do the reply.

Straits Institute of Minjiang University carried out the liberal education with the core of "exquisite life", through the integration of internal, external and cross-strait highquality teaching resources. Straits Institute of Minjiang University invited Minqin Jiang, Qiu Yi, Shaolun Lee and other well-known experts and scholars and business executives to give liberal lectures. In addition, in order to make students adapt to the English Teaching in Taiwan, the school used "IELTS education" as the core of English teaching, based on Australian university English education system, with the fusion of East China Normal University high-quality foreign language resources ${ }^{[4]}$, and carried out small class, Chinese - foreign English teaching methods, to strengthen students' English ability and to meet the international standards. At the same time, the school launched the "cross-strait industry-academy cooperation plan", and established a cooperative working mechanism of Taiwan- funded enterprises and domestic enterprises. What's more the school sighed the industry - academy cooperative agreement with Taiwan VIA group, UFIDA, Kingdee, Constant Real Estate, Gold Online, FuhuaTextile, Tonglian Stationery, Meike Food etc. The relative cooperative units should bear the practice teaching and training courses. And the school should strengthen the horizontal cooperation in the research study with various cooperative units.

Shortcomings: due to policy differences between Fujian and Taiwan, parts of the Taiwan professional qualification certificates don't apply in the mainland, while the students who learn in Taiwan in the third year reduce the chance of taking the mainland certificates; because of the mainland and Taiwan materials with different names, it's easy to make errors in the formulation of the talent training program, for instance, the course which has been learnt in the mainland university is taught repeatedly because of the various course names..

\section{B. Shih Hsin University and Fujian Normal University}

Shih Hsin University and Fujian Normal University are cooperated in the mode of " $2+1+1$ " (that is, the first twoyear study in mainland China, the third- year study in Shih Hsin University, the fourth-year return to the mainland), with jointly determination of the training objectives, the development of the talent training program, and the construction of the curriculum system. In the profession of communications, one in three teachers should be from Shih Hsin University, and one in three courses, teaching materials and periods also should be undertaken by them to ensure the cooperation between Fujian and Taiwan. That is to say that the courses, teachers, teaching materials and teaching methods of Shih Hsin University accounted for about 1/3;

The high-quality courses of tourism introduced from Shih Hsin University should not be less than $1 / 3$, and not less than $1 / 4$ professional courses shall be undertaken by Shih Hsin University teachers. In order to strengthen the cultivation of practical talents for the news media of Taiwan, Taiwan set up the committee of experts of the cooperative project between Fujian and Taiwan which is made up of President Meiyu Wang, the Taiwan times China, President Qinglong Huang, Dean of Journalism and communication Institute of Shih Hsin University and other 7 Taiwan news media famous experts. And they are arranged to go to Fujian Normal University to give lectures and instruct the set of professional programs.

Fujian Normal University organized students in the "Non Fujian-Taiwan class" to attend the same lessons in order to select the students to go to Taiwan for exchanges and to expand the communicating effect in promoting the college practical courses of the cooperative project between Fujian and Taiwan. In addition, the college organized the young teachers to engage in advanced study in Taiwan as the leading teachers, in the hope that those teachers could be familiar enough with Taiwan and they could meet the requirements of Taiwan communications in their daily practical course teaching. 
Disadvantages: there are few Taiwan- funded hotel, tourist attractions, travel agencies in the mainland, and the internship of the tourism major can only be arranged in the mainland enterprises; although the innovation of professional talent training can be conducted, the limit of the scope of policy, insufficient reform and innovation prevented the project from playing the leading and pilot role;

The mode of education in Taiwan is more open and flexible. Teachers generally do not rigidly adhere to the form of classroom teaching. Taking tourism teaching as an example, the teachers often conduct outdoor practice, classroom activities and other diversified teaching methods, which would affect the learning discipline in a certain degree because such kinds of class would cause bustling class and unsatisfactory result for the poor disciplined students.

\section{Mingdao University and Wuyi University}

In order to highlight the characteristics of cooperation between Fujian and Taiwan, Mingdao University and Wuyi University arranged at least one course taught by the outstanding teachers from Mingdao University in the different semesters before leaving for Taiwan. And the teacher not only undertakes the task of teaching, but also bears the task of introducing his university In order to promote the interactive teaching activities, the university arranges two teachers-act as the role of A and B in the courses taught by Taiwan teachers, which means that the other professional teacher of Wuyi University will participate in the full courses and lectures, and while the Taiwan teachers can't complete the teaching task in the two-week intensive teaching, teacher B should continue to conduct.

Shortcomings: Wuyi University talent training program requires centralized practice, while Taiwan doesn't require so. And Mingdao University uses a decentralized arrangement in the course of practice, close combination with relevant professional content; as for the individual professional, the tea specialty emerged a disoperation in the professional direction of the first term of the third year 's Mingdao University course program. That means that they didn't allow students to select the series of courses in accordance with their own interest but only required them to select some courses in various directions.

\section{Chia Nan University of Pharmacy \& Science and Fujian University of Traditional Chinese Medicine}

June, 2008, Chia Nan University of Pharmacy \& Science and Fujian University of Traditional Chinese Medicine signed an agreement on jointly opening the profession of food science and engineering. So far, the profession has trained three sessions of students and 171 graduates. And a total of 46 batches, 46 Taiwan teachers came to the mainland to give lessons, including 8 courses with a total of 24 credit courses undertaken by Chia Nan University of pharmacy and science. In 2011, the two sides cooperate in the opening of food science and Engineering Specialty (undergraduate education project, $3+1$ ). In the autumn of 2014, the professional will deliver about 43 students to leave for Taiwan to conduct one- year exchange of learning. In order to promote cross-strait college students' communication, every year Fujian University of Traditional Chinese Medicine regularly send outstanding undergraduate students to study in Taiwan for exchanges, with each batch of 5 , and one semester of learning period. So far, Taiwan has selected 8 batches, 40 people of outstanding undergraduate students to study in Fujian University of Traditional Chinese Medicine for exchanges.

Shortcomings: because the first session of the undergraduate students in the " $3+1$ " project have not yet left for Taiwan, and the two universities lack enough experience, many potential problems have not been excavated. Therefor talent training system cohesion will be the concern in the cooperation between the two universities.

\section{E. Chaoyang University of Technology, Liming Vocational University and Putian University}

Chaoyang University of Technology cooperated with Liming Vocational University and Putian University. And it regarded the combination of learning with working as the breakthrough point in the construction engineering and technical talent training program of Liming Vocational University, and established professional teaching content and curriculum system guided by the main line of professional ability training. A large number of Taiwan highquality courses have been introduced, and the total professional courses credits are up to 74 credits, including 23 credits in the introduced Taiwan courses accounting for $31.5 \%$; The total number of professional courses reached 29 , including 10 Taiwan courses, accounting for $34.5 \%$, and 7 courses were taught by teachers from Taiwan, reaching $25 \%$. Such talent training mode as the construction cooperation and combination between university and enterprise, learning with training and internship training, and the courses and the training arranged and set up according to the job needs. Help to develop the students' abilities from one post to multiple posts and to comprehensive posts, and help to make the course more practical, more opening and more professional so that the experiment, the training and the internship could be guaranteed.

In 2011, Chaoyang University of Technology in cooperation with the Putian University set up Fujian and Taiwan classes, introducing high-quality Taiwan university teaching resources, adopting the mode of " $3+1$ ", in order to train students to adapt to the needs of the modern development, with the full play of mind and body development. And hope to train the senior talents with excellent professional skills, amazing selfcultivation and outstanding creation awareness, who are possessed with the accomplishment of art and design, master professional core ability, professional theory and professional basic computer application of environmental art design, and master system design skills and expand a new concept.

Disadvantages: the professional courses in cooperation with the Liming Vocational University are mostly related to the relevant national building codes. Because of the different building codes, the course will have to be arranged in the mainland universities. Thus the teaching effect will be affected 
due to the limit learning time and the students of low quality; According to the requirement of the cooperation program, the students should learn in Taiwan in their fifth semester, as a result, their graduation comprehensive training can only be arranged in the sixth semester, which resulted in such situation as students cannot meet the requirements for half- a- year internship; students are not willing to study in school, or because of family economic reasons they cannot be scheduled to learn in Taiwan, thus the school had to take measures to make this part of the students learn in the elective course in the mainland university, which cannot achieve the desired effect. Although Putian University has given strong support in the construction of laboratory of environment design, the overall investment is still less than normal. Updating and supplement of experimental instruments and equipment are badly in need. With the change of the school level and the social need for talents, the concept of teaching is badly needed to change. It is imperative to improve teaching methods, to transform the training objectives to train the applied talents, and to cultivate the talents with double-professional-title, finally to improve the talents' ability of application.

\section{THE ANALYSIS OF THE STUDENTS EDUCATIONAL ADMINISTRATION IN THE MODE OF UNIVERSITIES COOPERATIVE EDUCATION BETWEEN FUJIAN AND TAIWAN}

Colleges and universities cooperative education between Fujian and Taiwan is a new educational mode, which is still in the initial stage. And the experience to conduct the educational administration for students in Fujian and Taiwan is poor enough and the relative theory is backward, as well. Students who learn in Taiwan performed well in the accommodation, transportation, and medical insurance. Most of them can accept and integrate into the local life. There are high in learning and cherish the chance of exchange. What's more, they show great interest in the teaching in Taiwan. They consider that the exchange can be very good to broaden their horizons. However, problems and contradictions still emerged in the educational administration. Mainly in the following aspects.

\section{A. The contradiction between the teaching mode and the requirements and the differences of students' overall quality}

The discrepancy in the teaching mode of cooperative education between Fujian and Taiwan and the strictness on the teaching requirements and evaluation challenged the students a lot and put forward higher requirements. The students in the Fujian-Taiwan class had a relatively poor performance in the entrance examination, and their overall quality is relatively low, which gives them high pressure. The lack of teachers resource resulted in poor administration. Only one or two instructors participated in the administration. If those instructors are of low overall quality, the administration will be risky. All of the above affected the administration negatively.

\section{B. The contradiction between cross-strait education mode and students ideological and political education continuity}

The " $3+1$ "education mode breaks the continuity of students education administration, because of the limit of space, which caused some difficulties in the ideological and political education work. Meanwhile, after the students who learn in Taiwan contact a nearly strange and new environment for one year, they have been affected unconsciously from living habits to political stand and from their behaviors to their ways of thinking. As a result, it's imperative to master the students' ideological trend so as to strengthen the guidance. Especially the diploma students who spend four years learning in Taiwan should be paid more attention. It's extremely urgent to have a deeper understand of that students are thinking of, and to reinforce the patriotism education to the students, especially for the diploma students and the students upgrading from the junior colleges to universities.

\section{The contradiction between the difference of family economic situation and the change of consumption environment}

Various family economic situations result in a great discrepancy on the students consumption habits. There is great difference in the consumption environment and the price level between the mainland and Taiwan. In Taiwan, the higher awareness of luxury consumption urges students from the mainland to be a spendthrift, to wear designer-label clothes, and easily to involve in the endless game of one-upmanship. The discrepancy of the wealth and superiority complex influence the harmony of the class, which is also one of the difficulties of students administration.

\section{The contradictory results from the discrepancy of cross- strait culture and living habits}

Although Fujian and Taiwan are in the same origin, and have the same characteristics in the language, traditional festivals and folk traditions, there are still some differences. Due to historical reasons the culture of Taiwan is more diversified. As a result, it is also a test for the mainland students to adapt to the Taiwan diet and climate.

\section{THE COUNTERMEASURES AND SUGGESTIONS REGARDING REINFORCING THE MODE OF COOPERATIVE EDUCATION BETWEEN FUJIAN AND TAIWAN AND THE STUDENTS EDUCATION ADMINISTRATION}

\section{A. Reform the mode of talent training}

The cooperation between Fujian and Taiwan is really a great reform of talent training. In 2010 the "several opinions about Fujian Provincial Department of education on promoting the cooperation of cross-strait universities" pointed out that colleges and universities should explore actively and carry out the various forms of cooperation, develop innovation mode continuously, expand the area, and promote the complementary advantages of Fujian and Taiwan University, so as to realize the resources sharing. 
The reform provides new ideas, new initiatives and new measures to promote the leading role in the education of colleges and universities to Taiwan and achieved certain results. And the different understanding of the reform of colleges and universities, and different intensity of investment result in various effects. ${ }^{[5]}$ The top-level design of the talent training requires developing the comprehensive quality and practicing ability as the core, to cultivate advanced applied talents to meet the future employment market demand, and to further realize the professionalization of higher education. On this basis, we can learn from the perfect system of occupation education in Taiwan, focus on training the students' comprehensive quality and cultivate their practical ability, in order to apply it. ${ }^{[6]}$ That can be the reform orientation for various colleges and universities cooperative education and talent training between Fujian and Taiwan.

First of all, we should strengthen the introduction of high -quality professionals in Taiwan. We can strengthen the adjustment of relative universities and professionals participating in the program. In the choice of cooperative universities, we should choose the high- level and unique ones which are outstanding in a certain field. In the subject planning, we should start from the existing industrial structure of Fujian Province, and should consider whether Taiwan cooperative university has the internationalization level and has high-quality professional with a good fame, so that the cooperative professionals can be interactive complementary, and can be in a good combination.

Secondly, we should strengthen the convergence of the cross-strait university curriculum system. The talent training program and the teaching plan should be well-designed and repeatedly demonstrated to make certain that the highquality teaching resources can be applied and further extend to the interrelated research system.

Thirdly, we should strengthen the joint and promotion of cross-strait college teachers. The introduction of the internalized teachers, the new teaching methods, and ways of thinking and international perspective from Taiwan universities can vitalize the mainland university teachers. The Mainland Colleges and universities should also strengthen mutual communication, which help to enjoy the internationalization of high- quality teaching resources at home.

Fourthly, we should strengthen the practical training of cross-strait students. Taiwan colleges and universities have always attached great importance to the construction of practical mechanism. Since 2002, Taiwan's Ministry of education has set up 6 regional cooperation centers, located in the 6 Universities of science and technology, in various regions, which promote the management of learning- inwork and the integration of all resources, and boost the teaching practice and gain great achievements. ${ }^{[7]}$

\section{B. Build a new model of education and management of students in Fujian and Taiwan}

The management departments of the universities should strengthen the research on the new running mode, and do a dynamic learning tracking on the Fujian and Taiwan students, and should strengthen ideological and political guidance. And they should make great efforts to build a new model to adapt to the management of the students in the cooperation program between Fujian and Taiwan. ${ }^{[8]}$

First of all, the patriotic education and safety education should be attached great importance before the students leaving for Taiwan. Through that education, the students' thoughts and their security awareness can be improved, and the students can be clear about their purpose of exchange, so as to normalize their behavior. In the selection of the students to Taiwan, we should actively select the students with high political consciousness, outstanding achievements, and comprehensive quality.

Secondly, use Scientific Outlook on Development as a guide to actively lead cross-strait students' Ideological and political theory. And earnestly implement the party's education policy. At the same time, the cross-strait university should have a try first, and actively carry out the ideological and political education of students in a full range so as to build mutual exchange between Fujian and Taiwan. And let the cross-strait young people deepen the understanding of the cross-strait relationship and current status, thus enhance the spirit of patriotism.

Thirdly, the construction of the managerial staff should be reinforced. The training platform of studying further in Taiwan should be built. We should select the managerial staff with high consciousness and excellent management to study in Taiwan, in order to learn scientific administrative concepts and advanced experience of colleges and universities in Taiwan.

Fourthly, the management mechanism should be improved. And the specialized agencies should be set, and specialized personnel should be responsible for the selection of students, and should answer for the formalities to study in Taiwan. The exchange and the docking of Fujian and Taiwan universities, long-term management, and the contingency plan of the students' safety should also be considered. Relevant measures should be studied and formulated, and a long-term mechanism of service and management of Fujian and Taiwan students should be constructed.

\section{CONCLUSION}

The cooperative education of the cross-strait universities is to meet the needs of social development, and is an important measure to promote cross-strait educational exchanges and cooperation, which presents the complementary advantages. The study on the optimization of the cross-strait cooperative talent training program and the innovation of the educational management mode has great significance in the further communication and cooperation of cross- 
strait universities, and in the in-depth emotional communication and integration of cross-strait compatriots, and the development of the cross-strait future grand pattern.

\section{REFERENCES}

[1] Muming Lin, Huang Hui. On the Significance of Cooperative Education between Chinese Mainland and Taiwan and the Countermeasure of Sustainable Development [J] Journal of Fujian Radio \& TV University, 2010(6):39-41.

[2] Lai Jianqiang. More than 400 universities across the Taiwan Straits have signed inter-university exchange and cooperation agreements [EB / OL] http://www.gov.cn/jrzg/2009-05/18/content_1317287.htm

[3] Department of Education in Fujian .Fujian - Taiwan Cooperation Program ", the two sides of the Taiwan Strait jointly train talents[EB / OL] http://www.fjedu.gov.cn/html/jyyw/jyt/2011/07/06/fa9f97df-ac604bd8-e040-a8c0906558f1.html
[4] Lin Xiaofang, Chen Fangfang. On Joint Training of Talents in Colleges and Universities between Fujian and Taiwan [J] Cross-strait Education Research, 2015(2)::2-9

[5] Liu Yan-hong.Research on the Implementation Path of Ideological and Political Education of Fujian-Taiwan Cooperation Project in Fujian Province [J] .Economic Research Review, 2016, (20): 76-77.

[6] LinZhong-yan, ChenYong-zheng. ResearchesonExchangingandCooperativeModeofCrossStraitsUndergraduateEducationinUniversities $[\mathrm{J}]$ Journal of Minjiang University,2010,(03):46-49.

[7] Xu Deyang Liu GuomaiComparative Study on the Present Situation and Feature of Applied Undergraduate Education between Fujian and Taiwan e[J] Education and Examinations),2008,(02):62-66.

[8] Zhang Yong-ting. Discussion on the Fujian-Taiwan Student Education Management Work under the Fujian-Taiwan Cooperative Schoolrunning Mode[J] Journal of Jimei University(Education Science Edition),2013,(03):89-92. 